\title{
Does the warming of local anaesthetic reduce the pain of its injection?
}

\author{
A. M. DALTON,* A. SHARMA, $\dagger$ M. REDWOOD,* \\ J. WADSWORTH, \& \&. TOUQUET* \\ *Department of Accident and Emergency, †Department of Anatomy and $\ddagger$ Academic \\ Department of Community Medicine, St Mary's Hospital, London, England
}

\section{SUMMARY}

One hundred and fifty-seven patients who warranted the injection of local anaesthetic were divided into two groups. One group received local anaesthetic at room temperature $\left(21^{\circ} \mathrm{C}\right)$ and the other at body temperature $\left(37^{\circ} \mathrm{C}\right)$. The pain resulting from the injection was assessed using a visual analogue scale. There was no significant difference in the level of pain experienced by the two patient groups. It is concluded that no advantage is gained by the warming of local anaesthetic before its administration.

\section{INTRODUCTION}

It has been suggested (Bloom et al., 1984; Finkel \& Berg 1987; Paul et al., 1988) that the pain of injection resulting from the use of warmed local anaesthetic is less than that from anaesthetic at room temperature. Such studies have used a wide range of temperatures, from $22^{\circ} \mathrm{C}$ (Paul et al., 1988), to $43^{\circ} \mathrm{C}$ (Finkel \& Berg, 1987). Because of the frequent use of local anaesthetics by accident and emergency departments, and the possible benefits of warming these agents, this suggestion was tested.

\section{PATIENTS AND METHODS}

One hundred and fifty-seven consecutive patients of both sexes, aged between 16 and 65 , were included and divided into two groups. Even-numbered patients (using the accident and emergency card number) were given room temperature $\left(21^{\circ} \mathrm{C}\right)$ lignocaine.

Correspondence: Mr R. Touquet, Consultant in Accident and Emergency, St Mary's Hospital, London W2 1NY, England. 
Odd-numbered patients received lignocaine from ampoules which had been stored in water bath maintained at $41^{\circ} \mathrm{C}$ and then removed, opened and drawn up into the syringe immediately prior to injection.

The temperature of $41^{\circ} \mathrm{C}$ was chosen by the following method: a 5-ml ampoule of lignocaine was warmed to a known temperature in a thermostatically controlled water $\stackrel{?}{+}$ bath. It was then removed and drawn into a $5-\mathrm{ml}$ syringe using a 0.8 by $40 \mathrm{~mm} 21$-gauge needle. This was changed to a 0.5 by $25 \mathrm{~mm} 25$-gauge needle, the solution immediatelyen squirted over the bulb of a thermometer, and the temperature measured. The procedure was repeated using different temperatures of anaesthetic.

Because of the lower temperature of the needles, syringes, attendants' hands and surrounding air, the temperature of the lignocaine consistently dropped by $4^{\circ} \mathrm{C}$ betweenwater bath and injection. Anaesthetic kept at $41^{\circ} \mathrm{C}$ therefore resulted in an injection of $\vec{\sigma}$ lignocaine at $37^{\circ} \mathrm{C}$ (body temperature).

Digital ring blocks and lacerations for suture were included in the study. In both groups, $1 \%$ plain lignocaine was injected at $1 \mathrm{ml}$ per $30 \mathrm{~s}$ using a 0.5 by $25 \mathrm{~mm}, 25-\rightarrow$ gauge needle.

Ring blocks were performed by injecting from the dorsal surface on each side of theo base of the proximal phalanx, and were used for lacerations requiring suture, debridement, removal of foreign bodies and for the reduction of dislocations.

Lacerations were anaesthetized by injecting local anaesthetic through the skin $\overbrace{\mathbb{\infty}}^{\mathbb{2}}$ between 0.5 and $1.5 \mathrm{~cm}$ from the wound edge on both sides. The volume of injection ranged from 1 to $10 \mathrm{ml}$.

Immediately after the injection, the patients were asked to rate their discomfort on $100-\mathrm{mm}$ visual analogue scale, varying from no pain at all $(0 \mathrm{~mm})$ to the worst pain ever. suffered by that patient $(100 \mathrm{~mm})$. Scores were analyzed using a non-parametric Man Whitney $U$-test.

Patients were excluded if they had ingested alcohol or analgesic drugs within $4 \mathrm{~h}$ of the trial, if their level of consciousness was affected in any way, or if they could not禺 speak English.

\section{RESULTS}

There was a $2-\mathrm{mm}$, or $2 \%$, overall difference in median values on the visual analogue scale between patients receiving warmed lignocaine and those receiving room temperature lignocaine (Table 1). Using the two-tailed Mann-Whitney $U$-test, there was no significant difference between the two groups $(P=0 \cdot 8)$.

Similarly, when analysed separately, there was no significant difference between the two groups in either those receiving ring blocks $(P=0.77)$ or those receiving skin infiltration $(P=0.93)$.

Variables which may affect the pain experienced during injection, such as age and sex of the patient and volume injected, were comparable in the two groups (Table 2). The site of infiltration was well distributed (Table 3) and the number of ring blocks were्ष comparable in fingers and toes (Table 4). 
Table 1 Visual analogue score

\begin{tabular}{|c|c|c|c|c|}
\hline & \multicolumn{2}{|c|}{$\begin{array}{c}\text { Warmed } \\
\text { anaesthetic }\end{array}$} & \multicolumn{2}{|c|}{$\begin{array}{l}\text { Room temperature } \\
\text { anaesthetic }\end{array}$} \\
\hline & Median & Range & Median & Range \\
\hline Ring block & 20 & $1-73$ & \multicolumn{2}{|c|}{$(n=26)$} \\
\hline Infiltration & 16 & $0-54$ & \multicolumn{2}{|c|}{$(n=54)$} \\
\hline Total & \multicolumn{2}{|c|}{$(n=77)$} & $(n=80)$ & $0-100$ \\
\hline
\end{tabular}

$n=$ number of patients.

Table 2 Age, volume and sex

\begin{tabular}{|c|c|c|c|c|}
\hline & \multicolumn{2}{|c|}{$\begin{array}{c}\text { Warmed } \\
\text { anaesthetic }\end{array}$} & \multicolumn{2}{|c|}{$\begin{array}{l}\text { Room temperature } \\
\text { anaesthetic }\end{array}$} \\
\hline & Median & Range & Median & Range \\
\hline Age (years) & 30 & $16-89$ & 27 & $14-83$ \\
\hline Volume (ml) & $3 \cdot 0$ & $0 \cdot 5-5 \cdot 0$ & 3.0 & $1 \cdot 0-11 \cdot 0$ \\
\hline Number of males & 54 & $(70 \%)$ & 58 & $(72 \%)$ \\
\hline Number of females & 23 & $(30 \%)$ & 22 & $(28 \%)$ \\
\hline
\end{tabular}

Table 3 Site for skin infiltration (101 patients)

\begin{tabular}{llc}
\hline Warmed & $\begin{array}{c}\text { Room temperature } \\
\text { anaesthetic }\end{array}$ & $\begin{array}{c}\text { anaesthetic } \\
\text { Scalp }\end{array}$ \\
Face & 5 & 7 \\
Chest & 7 & 2 \\
Arm & 9 & 14 \\
Hand & 18 & 11 \\
Leg & 7 & 8 \\
Foot & 1 & 1 \\
Total & 47 & 54 \\
\hline
\end{tabular}

Table 4 Site of ring block (56 patients)

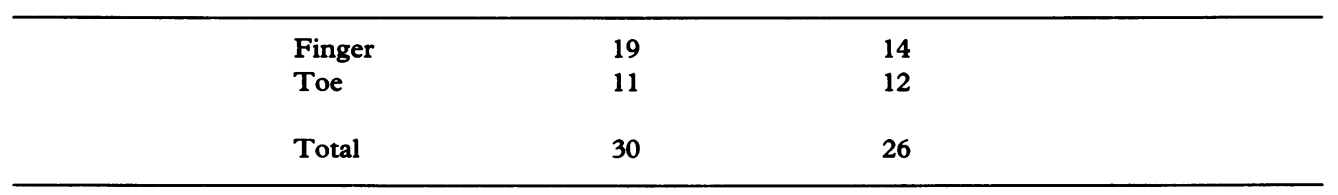




\section{DISCUSSION}

Injecting local anaesthetic at $37^{\circ} \mathrm{C}$, compared with that at room temperature, did no significantly reduce the pain of injection, either when infiltrating the skin or when undertaking ring blocks.

Paul et al. (1988) have showed that injecting $0.5 \%$ prilocaine at $37^{\circ} \mathrm{C}$ reduces the discomfort of Bier's blocks, in comparison with anaesthetic at room temperature, ander conclude that prewarmed local anaesthetic solutions cause less discomfort in general $\stackrel{\widetilde{\Phi}}{\square}$ Large volumes $(40 \mathrm{ml})$ of solution were used intravenously, however, and thereforew cannot be compared with much smaller doses of subcutaneous solution.

Bloom et al. (1984) state that preheating local anaesthetic agents used for retrobulbarand facial nerve injection greatly decreases patient discomfort, although they produce no evidence whatsoever.

Finkel \& Berg (1987) suggest that heating lignocaine to $43^{\circ} \mathrm{C}$ before infiltrative injection for local anaesthesia in arthrography, angiography and other interventional $P$ procedures reduces the burning sensation during its administration. Again, there is nof objective study.

Other factors, such as needle size, volume used and speed of injection, may affect the pain of injection (Gormley, 1987); however, injecting lignocaine subcutaneously at $37^{\circ} \mathrm{C}$, by comparison with that at room temperature, does not.

\section{REFERENCES}

Bloom L. H., Scheie H. G. \& Yanoff M. (1984) The warming of local anaesthetic agents to decrease discomfort. Ophthalmic Surgery 15, 603.

Finkel L. I. \& Berg D. J. (1987) Heating lidocaine appears to prevent painful injection. American fournal of̆ Roentgenology 148, 651.

Gormley D. E. (1987) Local anaesthesia: Pain control with proper injection technique. fournal of Dermatolo- $\overrightarrow{\overrightarrow{0}}$ gic Surgery and Oncology 1, 13, 35-6.

Paul D. L., Logan M. R. \& Wildsmith J. A. W. (1988) The effects of injected solution temperature on? intravenous regional anaesthesia. Anaesthesia 43, 362-4. 